\title{
Neuroepidemiology Advances into the 21st Century
}

\author{
G.C. Román, Editor-in-Chief
}

With the first issue of Neuroepidemiology in 2001, the journal begins its 20th year of continuous publication, advancing with confidence into the 21 st century and the new millennium. Neuroepidemiology was founded in 1982 by Bruce S. Schoenberg - then Head, Section on Epidemiology, National Institute of Neurological and Communicative Disorders and Stroke, National Institutes of Health, Bethesda, Md., USA - with the purpose of providing an international forum for this 'relatively new specialty... with a commitment to excellence and a dedication to clinically relevant topics' [1]. During its first year, and despite its youth, the high scientific standard set by Dr. Schoenberg and the international editorial board for the new publication was recognized with an Award of Merit from the Society for Technical Communication. This standard of excellence has been maintained by the successive editors, F. Clifford Rose (1984-1988), Milton Alter (1989-1996) and, most recently (1997-2000), by my predecessor, Philip B. Gorelick, under whose direction the journal achieved a high impact index among both epidemiology and public health publications and neuroscience journals. It is, therefore, with some trepidation that I have accepted the appointment as Editorin-Chief, to take the helm of the journal to continue along the bearings set by my illustrious predecessors.

From its beginnings, the quality of Neuroepidemiology has depended on its Deputy Editors, Editorial Board members and reviewers. For this reason, I am grateful to W.A. Rocca (Mayo Clinic, Rochester, Minn., USA) and W.T. Longstreth, Jr. (University of Washington, Seattle, Wash., USA), who have agreed to serve as Deputy Editors. Also, on behalf of the journal and its readership, I wish to thank the members of the Editorial Board that have completed their tour of service and to welcome the new members. One of the little-known roles of the Editorial Board members is to identify and encourage authors in their region - South America, Asia, India, the Middle East, Europe - to submit good-quality works to Neuroepidemiology; hopefully, this process will continue under the new group. Finally, I must recognize our publisher, S. Karger AG, Basel, and in particular Dr. Thomas Karger, for his long-standing commitment to the journal and for his personal interest in the continued success of Neuroepidemiology.

For the new century, Neuroepidemiology has changed to a larger format, and the journal sports a new cover conserving the traditional colors and the image of the globe to convey the importance of international collaboration. The new logo combines the neuron and the Gaussian bell, easily identifiable emblems of our trade, the Table of
Contents is now printed on the cover, and the online address for electronic access is prominently displayed. Authors and reviewers are being encouraged to submit materials via e-mail for faster communication. All these changes should result in faster turnover time between submission and publication. The popular 'Invited Reviews' will continue, as well as the 'Book Review' section. Abstracts from relevant literature will be presented in a new section titled 'World Review', to be published by agreement with the International Journal of Epidemiology (Oxford), Arquivos de Neuro-Psiquiatria (São Paulo), Revue Neurologique (Paris) and Revista de Neurología (Barcelona).

However, to remain and to thrive, a scientific journal - especially one of high quality - requires a loyal readership. During these 20 years, the members of the Research Group on Neuroepidemiology of the World Federation of Neurology have been the driving force behind the success of Neuroepidemiology, and in fact, the journal was recognized in its first issue as the Research Group's Official Publication, and for many years Neuroepidemiology has published gratis the abstracts of the annual meeting of the Research Group. It is hoped that this relationship will be formally recognized in future issues of the journal. Currently, Neuroepidemiology is the official publication of the Pan American Society of Neuroepidemiology, and of the Neuroepidemiology Group of the Italian Society of Neurology. Members of these groups receive subscriptions to the journal at half-price.

As predicted by Schoenberg [1], progress in neuroepidemiology is being rewarded by 'the opportunity to practice preventive neurology. By identifying and eliminating risk factors for neurological disorders, it is actually possible to reduce or even prevent disease'. We begin this new century with the promise of preventive neurology in Public Health and the possibility of extending to millions of people the practical benefits provided by neuroepidemiological research [2]. We expect Neuroepidemiology to be the vehicle of change in these exciting times.

\section{References}

1 Schoenberg BS: The scope of neuroepidemiology: From Stone Age to Stockholm. Neuroepidemiology 1982;1:1-16.

2 Román GC: Neurology in public health; in Detels R, Holland WW, McEwen J, Omenn GS (eds): Oxford Textbook of Public Health, ed 3, vol 3, The Practice of Public Health. Oxford, Oxford University Press, 1997, pp 1195-1223.

\section{KARGER}

(C) 2001 S. Karger AG, Basel

Fax +4161306 1234

E-Mail karger@karger.ch

www.karger.com
Accessible online at:

www. karger.com/journals/ned 